\title{
BMJ Global Health Incentivising wealthy nations to participate in the COVID-19 Vaccine Global Access Facility (COVAX): a game theory perspective
}

\author{
David McAdams (D) , ${ }^{1}$ Kaci Kennedy McDade (D) , ${ }^{2}$ Osondu Ogbuoji, ${ }^{2}$ \\ Matthew Johnson, ${ }^{3}$ Siddharth Dixit, ${ }^{2}$ Gavin Yamey (D) ${ }^{2}$
}

To cite: McAdams $D$,

McDade KK, Ogbuoji 0, et al. Incentivising wealthy nations to participate in the COVID-19 Vaccine Global Access Facility (COVAX): a game theory perspective. BMJ Global Health 2020;5:e003627. doi:10.1136/ bmjgh-2020-003627

Handling editor Seye Abimbola

- Additional material is published online only. To view, please visit the journal online (http://dx.doi.org/10.1136/ bmjgh-2020-003627).

Received 4 August 2020 Revised 19 0ctober 2020 Accepted 21 October 2020

Check for updates

(C) Author(s) (or their employer(s)) 2020. Re-use permitted under CC BY-NC. No commercial re-use. See rights and permissions. Published by BMJ.

${ }^{1}$ Duke Fuqua School of Business and Department of Economics, Duke University, Durham, North Carolina, USA

${ }^{2}$ Center for Policy Impact in Global Health, Duke Global Health Institute, Duke University, Durham, North Carolina, USA ${ }^{3}$ Duke Human Vaccine Institute, Duke University, Durham, North Carolina, USA

Correspondence to Dr Gavin Yamey; gavin.yamey@duke.edu

\section{INTRODUCTION}

Progress in developing COVID-19 vaccines has been rapid: the first clinical trial of a vaccine candidate began in Seattle, USA on 16 March 2020-just 63 days after China shared the genetic sequence of SARS-CoV-2, the virus that causes COVID-19. As of 12 November 2020 , there were 48 candidate vaccines in clinical trials. ${ }^{1}$ Given standard attrition rates, we can expect at least a handful of COVID-19 vaccines to eventually be launched.

However, developing a safe, effective vaccine alone will not be enough to end the pandemic. The vaccine must also be delivered globally at a price affordable to all governments and allocated in a way that maximises immediate and long-term public health impact and simultaneously achieves equity. In previous pandemics, these goals were not achieved. For example, in the 2009 influenza A (H1N1) pandemic, rich countries monopolised the vaccine supply; low-income countries (LICs) and middle-income countries (MICs) received fewer doses much later in the pandemic. ${ }^{2}$

The international community could have learnt lessons from this debacle and put in place a different kind of global vaccine allocation system for COVID-19. In an ideal system, manufacturers would openly share patents and manufacturing technology and adopt transparent, non-profit pricing; manufacturing would be globalised; and countries worldwide would pool funding to buy and allocate vaccines for everyone who needs them, free at the point of care. Unfortunately, we failed to learn from the H1N1 pandemic-rich nations are again flexing their market power by entering into bilateral purchase agreements with COVID-19 vaccine

\section{Summary box}

- Developing a safe, effective COVID-19 vaccine alone will not be enough to end the pandemic- the vaccine must also be delivered globally at a price affordable to all governments and allocated in a way that maximises public health impact and achieves equity.

- These goals are being threatened as rich nations enter into bilateral purchase agreements with COVID-19 vaccine manufacturers, potentially hoarding the global supply.

- It is impossible to stop these bilateral deals-the best we can achieve is to find ways to configure these deals to also benefit the new COVID-19 Vaccine Global Access Facility (COVAX), which aims to guarantee equitable access to COVID-19 vaccines worldwide.

- A game theory analysis suggested ways in which bilateral deals could potentially improve the global supply of vaccines, for example, if the manufacturer involved in the deal shares know-how or if the deal expands the global supply of critical inputs that might otherwise constrain production of COVAX vaccines.

manufacturers (table 1), potentially hoarding the global supply. ${ }^{3}$ Such 'vaccine nationalism' is a major threat to reaching global herd immunity and a return of normal social and economic activity. ${ }^{45}$

\section{THE COVID-19 VACCINE GLOBAL ACCESS FACILITY (COVAX)}

The new COVID-19 Vaccine Global Access Facility (COVAX) - led by Gavi, the Vaccine Alliance (Gavi), the Coalition for Epidemic Preparedness Innovations (CEPI), and the WHO-attempts to overcome vaccine nationalism. Acknowledging that bilateral deals cannot be prevented, since rich nations will inevitably act in their self-interest, it 
Table 1 Selected examples of bilateral COVID-19 vaccine purchasing agreements, as of November 12, 2020 (source: https:// launchandscalefaster.org/COVID-19)

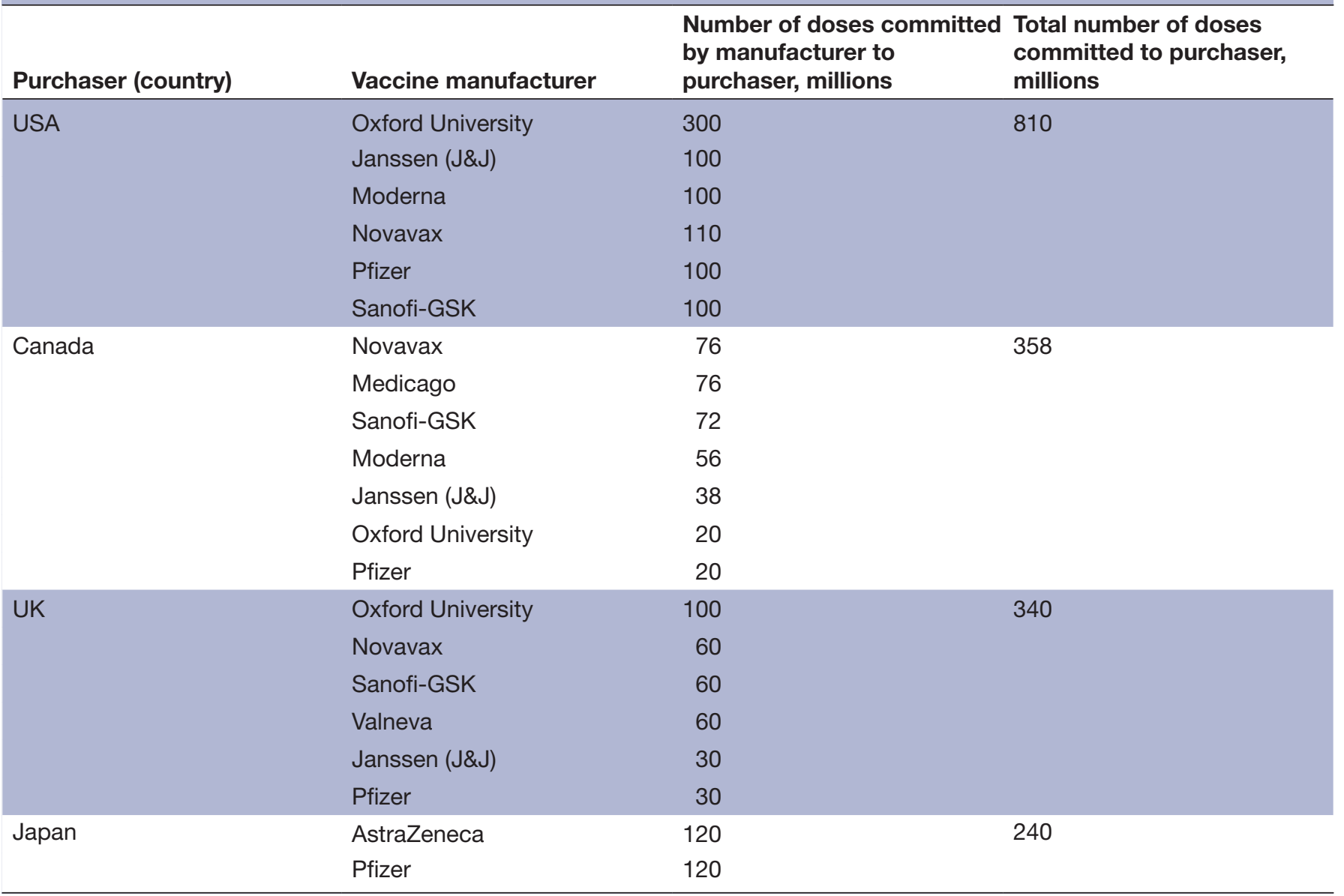

encourages these nations also to participate in COVAX to 'guarantee rapid, fair and equitable access to COVID-19 vaccines worldwide'. 6

COVAX aims to deliver two billion doses of vaccine to vaccinate one billion people (assuming a two-dose regimen) by the end of 2021 to participating countries. These doses will come initially from CEPI, a publicprivate partnership that is financing the development and initial manufacturing of a portfolio of COVID-19 vaccines (in the future, COVAX will obtain vaccines from additional sources, not just CEPI). Available doses of vaccines will be 'allocated to all participating countries at the same rate, proportional to their total population size'. The amount that countries receive should be enough to at least vaccinate all of the highest priority populations (eg, health workers and the elderly). About $5 \%$ of the facility's vaccine supply will be held in a reserve stockpile for deployment in acute outbreaks and humanitarian settings. 67

There are two ways to participate in COVAX, depending on a country's income status:

- Wealthier countries (high-income countries (HICs) and upper MICs) can participate as 'self-financing' countries. By joining COVAX, they commit to procure enough doses from the facility to vaccinate $10 \%-50 \%$ of their populations and also make an upfront payment to support vaccine development and manufacturing. The amount they pay is a reflection of the number of doses they want. These upfront contributions will support the facility to enter into agreements with vaccine manufacturers to secure future vaccine doses for participating countries. ${ }^{7}$ The more wealthier countries that participate, the more that the financial risks of investing in the development and manufacturing of multiple vaccine candidates will be shared (known as 'derisking') and the more doses that can eventually be purchased.

- Less wealthy countries (lower MICs and LICs) can participate as 'funded' countries, with their financial commitments covered by official development assistance (ODA). Within COVAX, a financing mechanism called the COVAX Advanced Market Commitment (AMC) will be used to raise funds, mostly ODA, to pay for vaccine supply to these funded countries.

Gavi states that it will try its best to support COVAX self-financing participants to choose a particular vaccine from the COVAX portfolio, even though it still remains uncertain which vaccines will be available, when, and at what scale. ${ }^{8}$ Gavi is also establishing a COVAX Exchange - a marketplace for both self-financing and 
funded countries-to 'facilitate trading of allocations of vaccine for all participants'.

If a wealthy country is already doing deals on its own to secure vaccine, often with a manufacturer based in that country (eg, the US government with the US company Novavax-table 1), participating in COVAX could still be valuable as an insurance policy. If the wealthy country's bilateral deals fail to produce a safe and effective vaccine, but the country has participated in the facility, it can still get enough doses from COVAX to vaccinate $10 \%-50 \%$ of its population.

Whether COVAX succeeds or fails depends in large part on how many and which wealthier nations agree to participate in the mechanism, and on whether bilateral deals end up crowding out global vaccine supply. By 30 September 2020, 74 countries had signed financially binding commitments. ${ }^{9}$ The USA has so far expressed no interest in COVAX. ${ }^{10}$ Meanwhile, 'many countries including Britain, the U.S., France, Germany, and others have directly negotiated their own deals with pharmaceutical companies to receive billions of doses, meaning that the vast majority of the world's vaccine supply next year is already reserved'. ${ }^{11}$

\section{INCENTIVISING PARTICIPATION BY WEALTHIER NATIONS IN COVAX}

Other than offering an insurance policy, are there other incentives that COVAX could provide to increase the number of wealthier countries that participate? We used game theory to address this question.

Game theory attempts to predict the behaviour of key actors in a particular setting, where the "payoff to strategies chosen by individuals depends on the strategies adopted by others in the population'. ${ }^{12}$ A game is any situation with multiple decision-makers ('players') whose choices impact one another. Game theory analysis has been used to address various global health challenges, such as in predicting (1) the prescribing behaviour of physicians in the face of rising antimicrobial resistance ${ }^{13}{ }^{14}$; (2) population behaviour under voluntary vaccination policies for childhood diseases ${ }^{12}$; and (3) when social distancing practices are most valuable during pandemics. ${ }^{15} 16$

In a game theory analysis, researchers first identify the strategic ecosystem of interest (in this case, the landscape of COVID-19 vaccine development, manufacturing and deployment); the relevant players and their objectives; players' strategic options; third parties capable of changing the game; and other factors such as the timing and observability of moves. The game we focused on is the current situation in which there are currently multiple vaccine candidates, yet no certainty as to which ones will be the safest and most effective. In this context, there are many players whose choices impact one another:

- Self-financing countries, deciding whether or not to participate in COVAX and/or to make bilateral deals with vaccine manufacturers.
- Vaccine manufacturers, deciding whether (and when) to agree to commit capacity through COVAX and/or to make bilateral deals with countries.

- Gavi and other global health institutions capable of influencing the 'rules of the game' directly (eg, through the specific rules of COVAX) and indirectly (eg, by articulating principles and facilitating collective action).

We did not include funded countries in the analysis because while they are impacted by the decisions of the players listed above, they have no control over the outcomes. Their choices do not impact others since they are automatically enrolled into the facility and their doses are fully funded.

In many ways, COVAX is attempting to address what the ecologist Garrett Hardin called a 'tragedy of the commons'. ${ }^{17}$ The commons is a shared resource that has value to everyone; its overuse by one actor can reduce its value to all others. Hardin wrote: "Ruin is the destination toward which all men rush, each pursuing his own best interest in a society that believes in the freedom of the commons. Freedom in a commons brings ruin to all." With COVID-19 vaccines, a tragedy of the commons can arise if HICs and upper MICs fail to support the COVAX Facility financially and/or if they make globally irresponsible bilateral deals that secure doses for themselves but fail to expand the global supply base. On the other hand, richer countries can promote the common public good by financially supporting COVAX's efforts to expand global vaccine supply and access, and by making bilateral deals that increase capacity, promote knowledge sharing and generate other positive spillovers.

Our game theory analysis articulates how COVAX can serve as a mechanism to promote such a commons, not just by enabling collective action but also by shaping HICs and upper MICs' incentives to make bilateral deals that benefit the broader global effort as well as themselves individually.

The detailed technical methods that we used to conduct our game theory analysis are shown in the online supplemental appendix. A preprint of this analysis was previously published online. ${ }^{18}$ Our analysis generated two key findings, on (1) the benefits of fungibility and harmonisation of investments, and (2) the potential value of adopting principles for bilateral deals that could promote global benefits. We discuss each of these further below.

\section{Fungibility of investments and supply-chain harmonisation}

Our game theory analysis suggests that Gavi and COVAX could enhance the 'value proposition' that COVAX offers to wealthier countries-thus incentivising them to participate in and fund the facility-by promoting fungibility and supply-chain harmonisation.

Everyone benefits when (1) COVAX investments to accelerate production of a specific vaccine candidate can be quickly repurposed to accelerate production of another vaccine ('fungibility'), and (2) critical inputs, processes and data are standardised across as many 
vaccine candidates and production facilities as possible ('harmonisation'). Gavi and CEPI have a number of options to increase fungibility and promote harmonisation, not just for their own investments but also for those being made by individual countries or coalitions of countries (eg, the EU) outside COVAX. Many of these steps are already being taken, such as putting explicit repurposing clauses in COVAX contracts and standardising vials and other downstream inputs. Such steps enhance the value proposition of COVAX for wealthier countries, in at least three ways.

First, increasing the fungibility of COVAX investments increases the value of each 'share' of COVAX output. If investing in vaccine $\mathrm{A}$ allows one to accelerate production of vaccine $\mathrm{A}$ or vaccine $\mathrm{B}$, then if vaccine A fails, having a 'share' in that investment gives a country accelerated access to vaccine B instead. In this way, fungibility magnifies wealthier nations' bang-for-the-buck from funding COVAX.

Second, increasing the fungibility of non-COVAX investments expands the potential reach of CEPI vaccines (ie, the vaccines that will be included in the COVAX portfolio). Imagine that vaccine $\mathrm{X}$ is outside of the CEPI portfolio and country $\mathrm{X}$ makes investments to accelerate production of vaccine $\mathrm{X}$. If vaccine $\mathrm{X}$ fails and the investments are non-fungible, then country $\mathrm{X}$ loses all of its investment and the rest of the world gets no value from that investment. By contrast, if vaccine $\mathrm{X}$ fails but the investments can be repurposed to accelerate production of a CEPI vaccine, then CEPI and country $\mathrm{X}$ will be able to strike a deal that enables the CEPI vaccine to be produced by country $\mathrm{X}$-with the output perhaps being split between country $\mathrm{X}$ and other nations through COVAX. The prospect of cultivating alternative uses for their own investments also gives wealthier nations more incentive to collaborate with COVAX.

Third, increasing harmonisation across the supply chain allows CEPI to deploy its own resources strategically, to fill gaps in others' supply chains. Countries that use CEPI resources to produce doses more quickly could be required to allocate some of those doses to poorer countries through COVAX. The prospect of a robust supply of inputs gives wealthier nations more incentive to collaborate with COVAX, and to adopt any standardisation (eg, vials, clinical data, regulatory procedures) that COVAX proposes.

\section{Adopting principles for bilateral deals}

How a bilateral deal impacts the rest of the world depends on how it is structured. This differential impact can be seen in the stark contrast between two of the bilateral deals made recently by the US government: the agreement between AstraZeneca and the Biomedical Advanced Research and Development Authority (BARDA) (the 'BARDA deal'), and the agreement between the US Department of Health and Human Services (HHS) and Pfizer/BioNtech (the 'HHS deal').
The HHS deal secures 100 million doses of the Pfizer vaccine for the USA (with an option to buy 500 million more doses), but makes no at-risk investment and hence does little to support vaccine development or to expand the availability of doses. This is a deal designed to benefit the USA and Pfizer, but no one else. By contrast, the BARDA deal funds advanced clinical studies, vaccine manufacturing technology transfer, process development and scaled-up manufacturing. This deal potentially benefits LICs and lower MICs in several ways, by funding higher risk activities and by generating vaccine products, processes and manufacturing capability that can then be broadly shared. Knowledge gained and shared in this way could help expand and accelerate production of the AstraZeneca vaccine for other markets, and perhaps also speed up production of other similar vaccines. This is a deal designed to benefit the USA, AstraZeneca and the rest of the world.

The wealthier countries supporting the COVAX Facility have an incentive to secure bilateral deals of their own. There is no way to stop wealthier countries from pursuing these deals, but COVAX can influence how such deals are made, so that more of these deals are beneficial to the rest of the world (like the BARDA deal) and not simply 'vaccine grabs' that take doses away from everyone else (like the HHS deal).

Our game theory analysis identifies two basic ways in which COVAX can shape wealthier countries' incentives to make bilateral deals with positive spillovers for the rest of the world.

First, drawing on insights from Elinor Ostrom's Nobel prize-winning work on how to support community selfenforcement of good-behaviour norms ${ }^{19}$ COVAX can articulate principles for how wealthier countries ought to structure their bilateral deals, and then create transparency as to which countries are making 'good' bilateral deals. Countries and leaders recognised for making good deals would rightly gain global prestige, while those who fail to do so would shame themselves. Providing clear guidance on how to structure bilateral deals for global benefit, and creating opportunities to 'socially sanction' those that choose not to do so, may be enough to incentivise many countries to do so.

Second, COVAX can work with partner countries to create extra benefits that only those who make 'good deals' are able to enjoy. For instance, suppose that a COVAX-supporting country makes a bilateral deal with substantial at-risk investment that expands overall production capacity. That country could then coordinate with COVAX to enhance the supply-chain resiliency of that new capacity and/or share technical information to enable that capacity to be quickly repurposed, if necessary, to produce a different vaccine. Countries that selfishly refuse to support COVAX's efforts would miss out on these extra benefits and, in the end, hurt themselves as well.

The question now becomes, how should we define a 'good deal'? The economic concepts of 'first best' and 
'second best' are useful in setting bounds on what we can hope to achieve. In an ideal world, each country would devote most of its COVID-19 investment dollars to the coordinated global effort-the 'first best'. In the real world, each country is captive to its own incentives. The 'second best' is the best we can achieve subject to incentive constraints. In this case, rich nations that fund COVAX have an incentive to also try to secure enough supplies for their entire population. The fact that such investments could have helped the world even more if they had been made within COVAX is irrelevant. The best we can hope for-the second-best-is to steer countries toward making bilateral deals with positive spillovers for the rest of the world.

\section{What are the spillovers?}

When a country makes a bilateral deal to accelerate production of doses to cover its own population, how does that deal directly or indirectly impact other countries?

If vaccine availability were fixed, then vaccine distribution would be a 'zero-sum game', with any deal that benefits richer countries necessarily harming LICs and lower MICs. In that context, the race by the rich world to strike bilateral deals clearly harms poorer nations, as (1) rich nations are able to secure the first supplies and (2) the race reduces the effectiveness of the global pandemic response. But vaccine availability is not fixed. The game that countries are playing is therefore not zero-sum, and the investments that richer countries are making to help themselves may also help poorer ones.

Four sorts of spillovers-three positive, one negativeare significant in the context of COVAX.
- Increased production flow (positive spillover). The bilateral deals that wealthier nations are making for COVID-19 vaccines typically entail massive at-risk investments to increase the quantity and accelerate the timing of vaccine availability. Such investments benefit these wealthier nations, but could also benefit other countries by expanding the global flow of vaccine production. For instance, suppose the USA were to make massive investments that sped up by 6 months the availability of a US-based vaccine with capacity to vaccinate 100 million people per month. The first batches would go to Americans but, because there are fewer than $600(6 \times 100)$ million US citizens, doses would start being exported before the vaccine would otherwise have been available.

- Increased optionality (positive spillover). Bilateral deals could be a means of identifying 'backup/pivot options' for CEPI and non-CEPI vaccine production. For example, suppose that an HIC that has chosen to fund and partner with COVAX also makes a bilateral deal with a vaccine maker to stand up some vaccine production facility, to be ready to accelerate production of that vaccine. Much of the work that goes into that preparatory process (eg, generating knowledge products, sourcing raw materials, and establishing supply chain systems) could then be shared with COVAX to ease efforts to build COVAX's own option to pivot to produce that vaccine. This sharing can occur: (1) if or when a CEPI vaccine fails yet a similar vaccine produced through the bilateral deal succeeds, and/or (2) to expand overall production through multiple supplying sites and partners. Neither the HIC nor the vaccine maker in

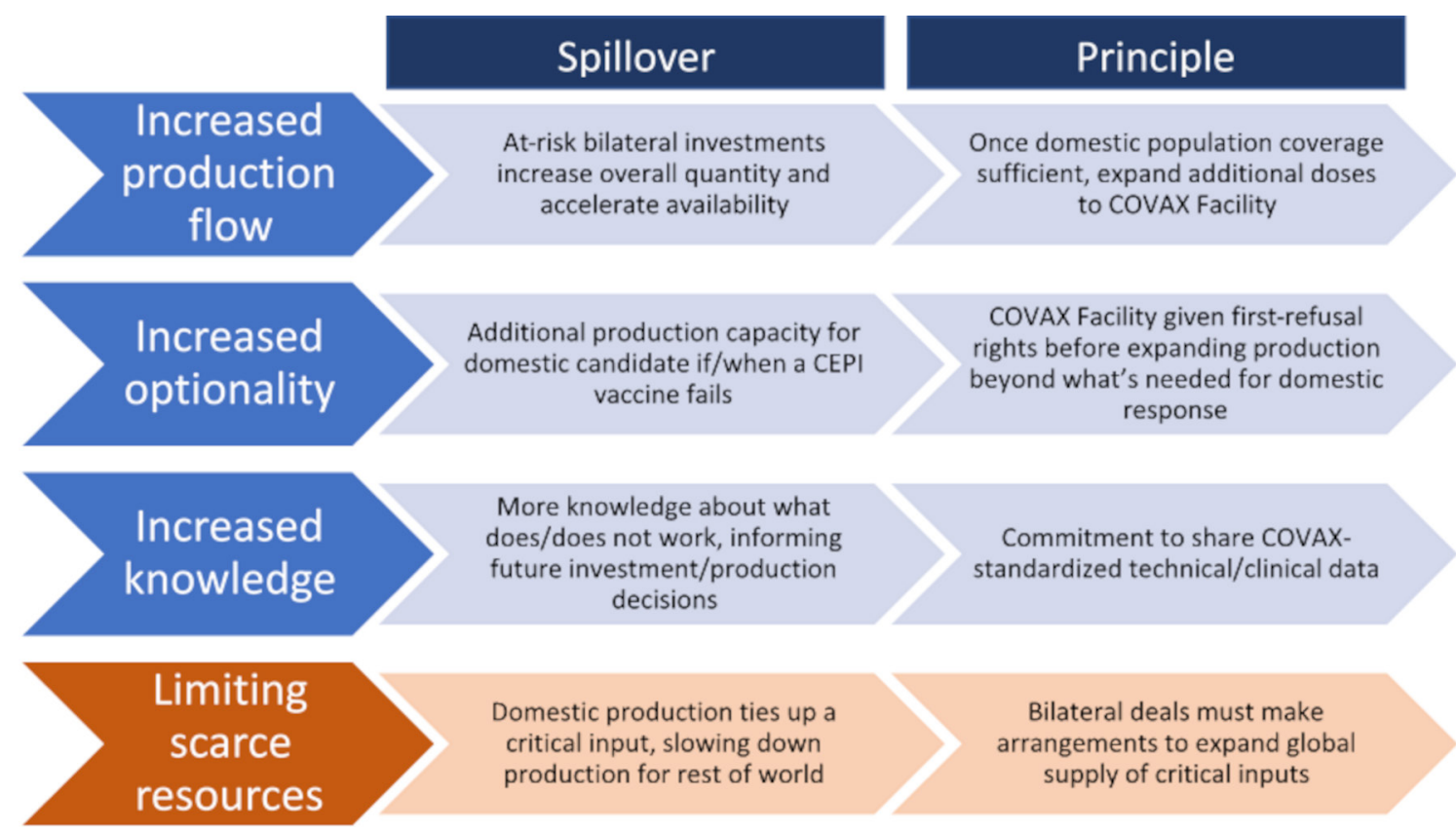

Figure 1 Investments by high-income countries to secure their own vaccine supplies: examples of potential spillovers and possible associated principles. CEPI, Coalition for Epidemic Preparedness Innovations. 
this scenario has any reason to object to complementary production in a COVAX-funded manufacturing facility. Indeed, both would benefit: the HIC, by speeding the global recovery (and hence helping its own economy), and the vaccine maker, by reaching additional markets and taking advantage of the COVAX AMC subsidy.

- Increased knowledge (positive spillover). Bilateral deals that accelerate learning about a vaccine candidate could benefit others-as long as the learning is shared-by improving others' decisions and speeding their ability to pursue producing and/ or using that vaccine themselves. For example, as experts in a COVAX-funded production facility learn how to accelerate production of a new vaccine candidate, what they learn could benefit COVAX partners seeking to produce another similar vaccine. This could be especially important for newer vaccine production platforms, both because more remains to be learnt about how to optimise production and because process and data-sharing standards are less likely to be well established. At the same time, those working with newer technologies have more incentive not to share details that could make it easier for others to backward engineer their intellectual property. A trusted third party such as COVAX could play an important intermediating role, to encourage information sharing.

- Tying up scarce inputs (negative spillover). If domestic production ties up a critical input, then accelerating production for a rich country will slow down production for the rest of the world, setting up a zero-sum game. Negative spillovers could also arise if a country's efforts to secure its own supply disrupt the global supply chain. For instance, an unscrupulous country might try to buy up all of some input as a means of pressuring others to supply them with early doses and/or induce some supplier in the COVAX supply chain to dishonour its agreements and instead serve their own individual interests.

Figure 1 summarises the spillovers and the potential associated principles described above.

What will well-intentioned wealthier countries be willing to do?

Articulating best practice principles for bilateral deals can influence how richer nations craft such deals, to improve outcomes for lower MICs and LICs, but only if richer countries can accommodate the principles in question without too much trouble or cost. For instance, to maximise positive spillovers due to increased knowledge, a principle might be that the manufacturer share COVAX-standardised technical and clinical data. Similarly, to minimise any negative spillovers due to tying up scarce resources, a principle could be that any bilateral deal include arrangements to expand global supply of critical inputs that might otherwise constrain COVAX production.

\section{CONCLUSION}

The proliferation of bilateral deals between richer nations and COVID-19 vaccine manufacturers is a major threat to ensuring global distribution of vaccines and to achieving herd immunity at a global scale. Such deals cannot be stopped, but insights from a game theory analysis suggest ways in which these deals could be configured to potentially improve the global supply of vaccines, by increasing fungibility of investments, enhancing supplychain harmonisation and articulating principles for such deals.

Twitter Kaci Kennedy McDade @kennedy_kaci and Gavin Yamey @gyamey

Contributors DM led the game theory analysis, wrote the first draft of the paper and wrote the supplemental material. GY wrote the second draft, and all authors contributed to the third draft. All authors participated in the analytic exercise that led to this paper. KKM and SD conducted background research on bilateral vaccine manufacturing deals. MJ provided expertise on vaccine manufacturing processes.

Funding This study was funded by the Duke Global Health Institute, Duke University.

Competing interests GY declares that he was a member of the COVID-19 Vaccine Development Taskforce, hosted by the World Bank, and participated in the consultation process that led to the launch of COVAX. GY and 00 have received grant funding from Gavi, the Vaccine Alliance.

Patient consent for publication Not required.

Provenance and peer review Not commissioned; externally peer reviewed.

Data availability statement There are no data in this work.

Supplemental material This content has been supplied by the author(s). It has not been vetted by BMJ Publishing Group Limited (BMJ) and may not have been peer-reviewed. Any opinions or recommendations discussed are solely those of the author(s) and are not endorsed by BMJ. BMJ disclaims all liability and responsibility arising from any reliance placed on the content. Where the content includes any translated material, BMJ does not warrant the accuracy and reliability of the translations (including but not limited to local regulations, clinical guidelines, terminology, drug names and drug dosages), and is not responsible for any error and/or omissions arising from translation and adaptation or otherwise.

Open access This is an open access article distributed in accordance with the Creative Commons Attribution Non Commercial (CC BY-NC 4.0) license, which permits others to distribute, remix, adapt, build upon this work non-commercially, and license their derivative works on different terms, provided the original work is properly cited, appropriate credit is given, any changes made indicated, and the use is non-commercial. See: http://creativecommons.org/licenses/by-nc/4.0/.

\section{ORCID iDs}

David McAdams https://orcid.org/0000-0003-0997-3071

Kaci Kennedy McDade http://orcid.org/0000-0002-0469-229X

Gavin Yamey http://orcid.org/0000-0002-8390-7382

\section{REFERENCES}

1 WHO. Draft landscape of COVID-19 candidate vaccines. Available: https://www.who.int/who-documents-detail/draft-landscape-ofcovid-19-candidate-vaccines

2 Fidler DP. Negotiating equitable access to influenza vaccines: global health diplomacy and the controversies surrounding avian influenza H5N1 and pandemic influenza H1N1. PLoS Med 2020;7:e1000247.

3 Yamey G, Schäferhoff M, Hatchett R, et al. Ensuring global access to COVID-19 vaccines. Lancet 2020;395:1405-6.

4 Goodman PS, Thomas K, Wee S-L, et al. A new front for nationalism: the global battle against a virus. New York Times, 2020. Available: https://www.nytimes.com/2020/04/10/business/coronavirusvaccine-nationalism.html

5 Bollyky TJ, Bown CP. The tragedy of vaccine nationalism, 2020. Available: https://www.foreignaffairs.com/articles/united-states/ 2020-07-27/vaccine-nationalism-pandemic

6 Gavi, the Vaccine Alliance. COVID-19 vaccine global access (COVAX) facility. Preliminary technical design. discussion document, 
2020. Available: https://www.keionline.org/wp-content/uploads/ COVAX-Facility-Preliminary-technical-design-061120-vF.pdf

7 Berkley S. COVAX explained. Gavi, the vaccine alliance, 2020. Available: https://www.gavi.org/vaccineswork/covax-explained

8 Gavi, the Vaccine Alliance. COVAX facility explainer. participation arrangements for self-financing economies. Available: https://www. gavi.org/sites/default/files/covid/covax/COVAX_Facility_Explainer. pdf

9 COVAX. Commitment agreements. Available: https://www.gavi.org/ sites/default/files/covid/pr/COVAX_CA_COIP_List_COVAX_PR_3009.pdf

10 The Washington Post. U.S. says it won't join WHO-linked effort to develop, distribute coronavirus vaccine. Available: https://www. washingtonpost.com/world/coronavirus-vaccine-trump/2020/09/01/ b44b42be-e965-11ea-bf44-0d31c85838a5 story.html

11 AP News. China joins COVAX coronavirus vaccine alliance. Available: https://apnews.com/article/virus-outbreak-xi-jinpingtaiwan-china-archive-aae1708207d3510a434d35aec994d4d1

12 Bauch CT, Earn DJD. Vaccination and the theory of games. Proc Natl Acad Sci U S A 2004;101:13391-4.
13 Colman AM, Krockow EM, Chattoe-Brown E, et al. Medical prescribing and antibiotic resistance: a game-theoretic analysis of a potentially catastrophic social dilemma. PLoS One 2019;14:e0215480.

14 McAdams D. Resistance diagnosis and the changing epidemiology of antibiotic resistance. Ann N Y Acad Sci 2017;1388:5-17.

15 McAdams D, Nash SIR. An economic-epidemiological model of strategic behavior during a viral epidemic. Covid Economics 2020;16:115-34.

16 Reluga TC. Game theory of social distancing in response to an epidemic. PLoS Comput Biol 2010;6:e1000793.

17 Hardin G. The tragedy of the commons. Science 1968;162:1243-8.

18 McAdams D, McDade KK. Incentivizing wealthy nations toparticipate in the COVID-19 vaccine global access facility (COVAX):A game theory perspective. Available: http://centerforpolicyimpact.org/wpcontent/uploads/sites/18/2020/08/COVAX-Facility_Game-TheoryAnalysis_FINAL.pdf

19 Ostrom E. Governing the commons: the evolution of institutions for collective action (political economy of institutions and decisions). 1 edn. Cambridge University Press, 1990. 